\title{
A problemática da produção da subjetividade em aula: reflexões acerca da docência universitária na área das Ciências Humanas
}

\author{
The problem of the production of subjectivity in class: \\ reflections on university teaching in the area of Human Sciences
}

Francisco Carlos dos Santos Filho
Fabiola Giacomini De Carli*
Flávia Eloisa Caimi ${ }^{* *}$

\section{Resumo}

O estudo aborda a problemática da docência universitária na área das Ciências Humanas, partindo de uma experiência educativa desenvolvida na disciplina intitulada Trabalho e Subjetividade, com alunos de um curso de especialização lato sensu na área de Gestão de Recursos Humanos, em uma instituição de ensino superior situada no interior do estado do Rio Grande do Sul. A reflexão é desenvolvida na interface da psicanálise e da educação, reconhecendo que a construção do conhecimento depende, em larga medida, da produção de efeitos de subjetivação nos envolvidos no processo educativo, no interior de uma relação de alteridade entre professor e aluno, que pode ser possível construir durante o encontro áulico.

Palavras-chave: Ação específica. Alteridade. Docência universitária. Subjetividade.

\section{Abstract}

The study is about the problem of university teaching in the area of Human Sciences, starting from an educational experience developed in the discipline named 'Work and Subjectivity', with students from a Specialization course in the field of Human Resources Management, issued by a University located in the interior of the state of Rio Grande do Sul. The reflection is developed on the interface of psychoanalysis and education, recognizing that the construction of knowledge depends - in large extent - of the production of effects of subjectivation on the involved with the education process, inside a relation of otherness between teacher and student, which can be possible to build during the class.

Keywords: Specific action. Otherness. University teaching. Subjectivity.

\author{
Recebido em: 13/01/2017 - Aprovado em: 25/05/2017
}

http://dx.doi.org/10.5335/rep.v24i2.7421

Doutor em Psicologia Clínica pela Pontifícia Universidade Católica de São Paulo. Professor do Curso de Psicologia da Universidade de Passo Fundo. Psicólogo e psicanalista. E-mail: franciscocsantosf@hotmail.com

** Mestranda em Educação na Universidade de Passo Fundo. Psicóloga e psicanalista. E-mail: fabiolagiacomini@yahoo. com.br

*** Doutora em Educação pela Universidade Federal do Rio Grande do Sul, com pós-doutoramento em Educação na Flacso, Argentina. Professora do Programa de Pós-Graduação em Educação da Universidade de Passo Fundo. E-mail: caimi@upf.br 


\section{Introdução}

Creo que la Universidad es un lugar de formación del espíritu. Creo que la Universidad no es un lugar de producción de técnicos. Creo que es un lugar de formación de pensamiento. Y creo que tenemos la responsabilidad los que podemos hablar desde el lugar de la docencia, de la transmisión de un conjunto de conocimientos que abran la perspectiva de quienes piensan (BLEICHMAR, 2009, p. 51). ${ }^{1}$

Cada área do conhecimento se constitui como campo disciplinar na medida em que elabora uma epistemologia própria, que lhe permite avançar e se desenvolver. Foucault (1996) nos ensina que todo o campo disciplinar possui um domínio de objetos, um conjunto de métodos, um corpus de proposições consideradas válidas e um jogo de regras, definições, técnicas e instrumentos. No que diz respeito às chamadas "ciências naturais", tais como a física, a química, a matemática, o avanço se dá no marco dos pontos de chegada das pesquisas produzidas anteriormente, ou seja, as mais recentes conquistas científicas, validadas e legitimadas pelos agentes do campo (pesquisadores), são o ponto desde onde as próximas pesquisas irão partir, por isso, são denominadas ciências cumulativas. Poderia até parecer óbvia a afirmação, não fosse o propósito que temos de mostrar que, no âmbito das ciências humanas e sociais, o avanço científico não ocorre da mesma maneira. $\mathrm{O}$ avanço das ciências ditas "do homem e da sociedade" se dá no marco de seus pontos de partida. Segundo Charlot,

[...] quando há avanço nessas ciências é por que foi proposta uma outra forma de começar (e por que se prova que ela produz resultados). Foi assim que fizeram Durkheim, Freud, Marx, Pavlov, Braudel, Levi-Strauss, Bourdieu, Garfinkel, Goffman, Lacan, Piaget, Vygotsky, enfim, todos os grandes nomes da história das ciências sociais e do homem (CHARLOT, 2006, p. 17).

As ciências humanas não são ciências cumulativas, mas de memória, afirma Charlot (2006). Memória, elemento humano por excelência, é tudo aquilo que, tendo um registro, poderá ser narrado, contextualizado, enlaçado, reconstruído, significado, ressignificado, compreendido, reconciliado, o que depende de um movimento ativo de apropriação.

O ensino das humanidades, a sua transmissão e as apropriações são fortemente impactados pelas características próprias do "objeto de estudo", que não é propriamente um objeto, pois se trata de um elemento humano, altamente complexo, que fala, pensa, age, reage. A apropriação dos conteúdos, muitas vezes, não depende apenas da apreensão de estratégias de construção cognitiva. Se as possibilidades de desenvolvimento humano se circunscrevem, de maneira singular, no interior da relação com um outro humanizante (LAPLANCHE, 1992), a construção do conhecimento depende, em larga medida, da produção de efeitos de subjetivação 
nos envolvidos no processo educativo, no interior de uma relação de alteridade entre professor e aluno, que pode ser possível construir durante as aulas (JANIN, 2013).

O conceito de subjetividade não tem origem na psicanálise, mas na Sociologia, e se refere aos efeitos da variação dos processos históricos e sociais, que se alteram de época para época, sobre a subjetividade humana. Sendo a subjetividade uma parte do psiquismo, e não o seu todo, que corresponde ao eu, sua construção está ligada à incidência dos enunciados sociais sobre o sujeito e às suas possibilidades de articulação e integração. Conforme Bleichmar, "[...] a produção de subjetividade faz com que as sociedades determinem as formas com as quais se constituem sujeitos passíveis de integrar-se a sistemas que lhes outorgam um lugar [...]. Vão produzir um sujeito histórico, aceitável socialmente" (2009, p. 54, tradução nossa). ${ }^{2}$ Esses câmbios produzem efeitos diretos sobre a educação em todos os níveis, do básico ao superior.

A subjetividade se constrói no intercâmbio humano, mais especificamente, num tipo de intercâmbio que considere a complexidade humana sem a preocupação de encontrar respostas simplistas e reducionistas para as questões que lhe concernem. Uma experiência de subjetivação favorece a abertura do espírito voltado à construção de enigmas, à condição de pensar por si próprio, de expressar o que pensa, de ser ouvido e de ouvir. Uma experiência de subjetivação faz contato. Intervenções subjetivantes, contudo, necessitam ser pensadas e construídas, com trabalho e criatividade, e exercidas desde o lugar de alteridade.

Atento às mudanças que se produzem na construção de subjetividades em nosso tempo, Libâneo (2011) aponta que as instituições de ensino superior precisam estar vigilantes e preparadas para atender às necessidades de aprendizagem no contexto atual, não podendo alienar-se de suas responsabilidades, ainda que essas sejam complexas. Como exemplo de tais responsabilidades, refere:

[...] o desenvolvimento da razão crítica, isto é, a capacidade de pensar a realidade e intervir nela, por meio de sólida formação cultural e científica; o provimento de meios pedagógico-didáticos para o domínio de competências cognitivas que levem ao "aprender a pensar"; o fortalecimento da subjetividade dos alunos e ajuda na construção de sua identidade pessoal, dentro do respeito à diversidade social e cultural; a formação para a cidadania participativa (LIBÂNEO, 2011, p. 189).

No contexto da formação profissional em cursos universitários de graduação e de pós-graduação, a atividade docente incide sobre as disciplinas com o desafio de estabelecer interlocução entre áreas diversas, com epistemologias diferentes e pontos de partida e de chegada próprios. O professor precisa preparar-se para produzir um delicado encontro com alunos de áreas do conhecimento diversas da sua, no intuito de que esse encontro seja produtivo e humanizante. 
Com base em tais premissas, propõe-se, no presente estudo, tratar o problema da docência universitária na área das Ciências Humanas partindo de uma experiência de trabalho desenvolvida com alunos de um curso de especialização lato sensu, na área de Gestão de Recursos Humanos, numa instituição de ensino superior situada no interior do estado do Rio Grande do Sul, cuja disciplina ministrada no ano de 2015 intitulava-se Trabalho e Subjetividade. ${ }^{3}$

A turma com quem os docentes - cuja formação provém das ciências humanas - se propunham a dialogar era formada por administradores de empresas, contadores, gestores de recursos humanos, egressos de cursos universitários técnico-administrativos, o que tornava ainda mais complexa e desafiadora a tarefa a realizar. O desejo era produzir um encontro que, respeitando a diversidade de cada área, pudesse ampliar as capacidades de analisar em profundidade o significado de gerir "recursos humanos" e reconhecer a partir de quais perspectivas essa ação poderia ser pensada, tendo em vista as noções centrais de trabalho e subjetividade.

Na condução da proposta de trabalho com a turma, partilhamos da posição psicanalítica, por suposição, não exclusiva da psicanálise, que toma por princípio a ideia de que o ser humano não nasce humanizado, que a humanidade, antes, é permanentemente construída e conquistada. Encontramos esse pressuposto também em Hannah Arendt, quando afirma que "[...] a criança, objecto da educação, apresenta-se ao educador sob um duplo aspecto: ela é nova num mundo que lhe é estranho, e ela está em devir. Ela é um novo ser humano e está a caminho de devir um ser humano" (2011, p. 37). Esse devir, ou o vir a ser, é um processo infindável, uma vez que, a qualquer tempo da vida, não apenas na infância, podemos nos desenvolver em nossa subjetividade em direção a uma humanização possível. Trata-se de uma construção, todavia, que necessita de referentes humanos para que se efetive. Essa era nossa aposta com o grupo de alunos com quem trabalhamos.

Partindo desse viés, apresentamos, a seguir, um relato reflexivo e teorizado de como transcorreram as aulas da disciplina Trabalho e Subjetividade, como e por que foi eleito o conteúdo a ser apresentado aos alunos e qual a opção metodológica adotada para tal. Na seção subsequente, propomos uma reflexão acerca do potencial do trabalho docente nas disciplinas ditas "humanas" dentro da universidade.

\section{Diagnosticando a trincheira}

Uma vez iniciados os trabalhos com a turma da disciplina Trabalho e Subjetividade, em um curso de especialização lato sensu em Gestão de Recursos Humanos, ${ }^{4}$ o retorno para ministrar a segunda aula exigia dos docentes a difícil tarefa de lidar com o mal-estar resultante da posição dos alunos, manifestada por clara indiferen- 
ça diante do recorte introdutório da disciplina proposto no primeiro encontro. Ao planejar a aula, tínhamos a expectativa de realizar uma articulação fecunda e profunda dos temas, de modo que a proposta produzisse sentido entre os estudantes. Essa expectativa não se concretizou, gerando a desconfortável sensação de que o investimento parecia estar sendo entregue a ninguém. Apesar do desconforto, a proposição subjacente apresentada pelo grupo de alunos - de que eles eram ninguém - foi firmemente recusada pelos professores. Essa foi a premissa de partida adotada para nortear o trabalho, uma vez que aceitar tal acordo tácito implicaria produzir um ato de exclusão, ação desumanizante. Isso desencadeou nos docentes uma série de questões que tangem o ensino em ciências humanas, circunscrita entre duas premissas não excludentes: "ensinar" as temáticas humanas e produzir subjetivação.

Naquele primeiro encontro com a turma, a disposição das classes estava em formato de $\mathrm{U}$, todos os alunos encontravam-se posicionados próximos às paredes da sala de aula, conectando seus computadores pessoais às redes de energia elétrica, o que produzia um efeito crescente de desconexão entre professor e alunos, sem encontro de olhares, sem contato humano produtivo, sem perguntas e comentários sobre o assunto. As tentativas de fomentar questionamentos entre os alunos, para desencadear processos de pensamento e aprendizagem, ficaram sem resposta. Não parecia inibição, desatenção ou qualquer tipo de apatia. A representação que se produzia era a de uma posição de entrincheiramento atrás das telas dos computadores, como estruturas defensivas que, se, por um lado, obstaculizavam a troca humana genuína, subliminarmente, por outro, colocava-nos em lados opostos, metonimicamente, na posição de inimigos. Assim foi a leitura possível do que se percebeu internamente do que foi visto, sentido, ouvido e processado naquele encontro inicial. Teríamos, então, um tempo razoável de trabalho pela frente. Como seria? Poderíamos, todos, não sucumbir ao descaso e à indiferença, tão letal quanto a violência de uma guerra? ${ }^{5}$ Conseguiríamos criar uma abertura para o novo e para interações qualificadas, mobilizando ambas as partes dessa relação? Com qual ação específica ${ }^{6}$ isso seria possível?

As inquietações seguiram. Como trabalhar uma disciplina de tal natureza sem contato com o outro, sem troca humana, sem ouvir o outro? Essa é a premissa de base dos processos de subjetivação, como também para aquele profissional que pretende gerir recursos humanos. Como construir um conhecimento significativo, de modo a produzir uma marca sobre esses profissionais que atuam ou atuarão com trabalhadores de empresas, se não podem estabelecer esse contato?

Era necessária a adoção de uma estratégia de intervenção nessa situação. Masetto (2003) refere que pensar em estratégias para as aulas não se reduz a escolher uma técnica pedagógica. A estratégia adotada precisa estar em acordo com os obje- 
tivos que se pretende alcançar na disciplina e considerar o contexto da turma, seu histórico, sua singularidade. Diz o autor que "as estratégias para aprendizagem se constituem numa arte de decidir sobre um conjunto de disposições, que favoreçam o alcance dos objetivos educacionais pelo aprendiz, desde a organização do espaço da sala de aula com suas carteiras até a preparação do material a ser usado" (MASETTO, 2003, p. 86). Além disso, o autor destaca que se espera do professor, para além da aplicação de técnicas e de domínio intelectual do conteúdo, uma atitude ativa frente à construção do conhecimento e uma intervenção dinâmica no campo das estratégias de ensino.

Sabíamos que aquele grupo requeria não apenas a aplicação de técnicas de ensino, mas necessitaria de um ato. Um ato potente, uma ação com a força de desestabilizar e desacomodar o que aparecia como fechamento ao outro humano, em posição de diferença, para tentar abrir para o pensar. Trabalhamos, então, com a noção de intervenção subjetivante (JANIN, 2013), que alude à ideia de uma tomada de posição com ativo envolvimento, na intenção clara de produzir efeitos de ampliação da subjetividade dos envolvidos, que contemple a complexidade do humano e a ética com o semelhante. Primeiramente, uma marca que rompa a indiferença, sem a qual não há construção nem registro possível da alteridade.

Alteridade é uma noção central em psicanálise, no que tange ao problema do vir a ser humano. Referindo-se ao registro psíquico interno da radical diferença do ser e do pensar do semelhante, a alteridade, fenômeno circunscrito dentro de uma estrutura histórica para o sujeito, produz-se e se instaura por meio do encontro intersubjetivo com o outro, capaz de reconhecê-lo em sua diferença e singularidade. Nas palavras de Prol e Wettengel:

[...] quem foi socializado e modelado no contato com os outros dentro de uma dada cultura adquire, em certa medida, a capacidade de dialogar com uma imagem mental do outro que supõe pontos de vista diferentes dos seus. Se não pode construir essa hipótese - a de um pensamento diferente - o intercâmbio com o outro ou com a representação que possa chegar a ter dessa possibilidade se torna impraticável. Permanece num espaço psíquico no qual a alteridade não ressoa porque só recebe o eco de si mesmo (2009, p. 11, tradução nossa). ${ }^{7}$

A condição para o registro da alteridade é a existência de um outro que, por uma diferença no âmbito do saber e também do poder, possa exercer a função de corte, que promova uma sorte de deslocamento narcísico. Quando corre bem, conduz à abertura do pensar para o reconhecimento do outro em sua condição humana, com suas necessidades e potencialidades. Esses são elementos para pensar a posição dos alunos na situação relatada, mas, especialmente, para refletir sobre a posição do professor, em suas estratégias de ingresso do registro da alteridade como intervenção que amplia as possibilidades subjetivas de compreensão e consideração do outro em sua alteridade. 
Era essa a complexidade de elementos de fundo que nos preocupava em relação ao que seria possível produzir nas aulas com aquele grupo e que, de resto, está presente em todas as relações humanas, em sua regulação. Sabíamos que sem a alteridade, sem esse reconhecimento, dificilmente haveria aprendizagem. Para haver encontro, precisariam baixar as telas, "baixar a guarda", baixar as defesas ao contato e dispor-se a ouvir, dar espaço ao outro, deixar-se atravessar, desfazer as trincheiras para ver que possibilidades teríamos de vitalizar esse encontro.

\section{A ação específica que resulta em intervenção subjetivante}

A segunda aula iniciou com o seguinte convite: "Deixem as máquinas de lado, peguem suas cadeiras e sentemos todos em círculo, no centro da sala”. Após alguns movimentos de resistência, em que justificavam, apoiados nos "tempos atuais", a necessidade da máquina para o bom aproveitamento da aula, foi-lhes assegurado de que a lida com gente não se esgota em fórmulas, dicas, anotações no computador. O registro precisaria se inscrever nas nossas consciências. Os conteúdos teriam de ser tateados, tocados, sentidos, contatados, pensados, articulados internamente. Essa é uma possibilidade, esse é o caminho sem garantias do trabalho com pessoas. Correndo todos os riscos de parecermos retrógrados e pouco simpáticos, fomos fazendo movimentos em direção à construção de recursos - internos - humanos, que fossem potentes para trabalhar com gestão de recursos humanos, como se costuma denominar as pessoas que trabalham nas empresas.

Esse breve relato se justifica na medida em que o ato em questão, ao qual conferimos o estatuto freudiano de ação específica, adquiriu também um estatuto de significante, ${ }^{8}$ que atravessou todo o trabalho e forneceu as bases para o deslocamento do grupo de um lugar a outro. Não pretendíamos um mero deslocamento no espaço da sala de aula, mas uma alteração dessa posição subjetiva de indiferença frente ao professor. Não queríamos que o convite ao movimento, ao deslocamento e ao reposicionamento ficasse restrito a atender ao pedido dos professores de forma submissa, mas que, num espaço-tempo de elaboração psíquica do vivido, por meio dessa ação específica, se produzisse certo nível de subjetivação associado à compreensão do fenômeno humano em curso naquele momento, deslocando todos os envolvidos da posição de indiferença rumo ao reconhecimento e à consideração do outro e em direção ao registro interno da alteridade.

Ao apresentar algumas noções sobre o psiquismo e o universo do trabalho com base em Freud, dizíamos aos alunos que o ordenamento da civilização humana produz imensos e inigualáveis ganhos a todos, cobrando, contudo, seus custos psíquicos a cada um de nós. A regulação das relações humanas no espaço social exige que 
todos sejam sacrificados, pois o indivíduo cede sua liberdade individual em nome do coletivo, pagando, por isso, um preço que está relacionado ao mal-estar próprio do processo de humanização. Este é o exato retrato do que estávamos propondo ao grupo: que se abrisse mão dos interesses individuais em nome de uma construção grupal que favoreceria a todos, mesmo que isso implicasse algum custo psíquico. Saber suportar e lidar com esse custo - essa é a "economia" interna de cada um está relacionado com as possibilidades de humanização.

Nas aulas, passou-se a buscar, incansavelmente, o objetivo de que a ação específica pudesse ser pensada em seus sentidos mais profundos, além de observar os movimentos do grupo e propor refletir sobre o que se passa e como isso poderia ser entendido à luz dos aportes teóricos apresentados.

Ao final de uma manhã de aula, após estudar um texto de Christophe Dejours (2000), intitulado A banalização da injustiça social, e trabalhar o conceito de banalidade do mal, em Hannah Arendt (1999), vinculado ao fenômeno da indiferença, apresentamos a leitura de um trecho do romance Nada de novo no front, escrito em 1928, por Erich Maria Remarque (2004), um ex-combatente alemão nas trincheiras da Primeira Guerra Mundial. Fruto de noites de insônia que evitavam os pesadelos com a guerra, Remarque preenchia cadernos contando, com admirável sensibilidade, os infindáveis horrores da guerra para aquele que consegue ver no inimigo um semelhante. No trecho destacado do romance, um corpo tomba ao lado de Paul na trincheira, baleado, e, nesse tempo em que seu inimigo agoniza no instante da morte, ele estabelece um diálogo profundamente comovedor consigo e com o homem prestes a morrer:

Cada respiração arquejante corta meu coração. Esse ser que agoniza tem o tempo do seu lado, possui um punhal invisível, com que me fere: o tempo e meus pensamentos. Quanto não daria eu para que se salvasse? É duro ficar deitado aqui, sendo obrigado a vê-lo, ouvi-lo. Às três horas da tarde ele morre. Respiro aliviado, mas só por pouco tempo. Em breve, parece mais doloroso suportar o silêncio do que os gemidos [...]. Não tem sentido o que faço, mas preciso ocupar-me. Assim, coloco o morto em uma posição mais confortável, embora ele não sinta mais nada. Fecho-lhe os olhos [...]. A boca é larga e suave, sob o bigode; o nariz um pouco curvado, a pele morena [...].

O silêncio prolonga-se. Falo, preciso falar. Assim, dirijo-me a ele e digo-lhe: - Companheiro, não queria matá-lo. Se saltasse novamente aqui para dentro não o faria, se você também fosse razoável. Mas, antes, você era apenas um pensamento, uma dessas abstrações que povoam meu cérebro e que exigem uma decisão... foi essa abstração que eu apunhalei. Mas agora, pela primeira vez, vejo que é um ser humano como eu. Pensei nas suas granadas, na sua baioneta e no seu fuzil. Agora vejo sua mulher, seu rosto e o que temos em comum. Perdoe-me companheiro. Só vemos as coisas tarde demais. Por que não nos repetem sempre que vocês são também uns pobres diabos como nós, que suas mães se inquietam como as nossas e que temos o mesmo medo da morte e morremos do mesmo modo, sentindo a mesma dor? Perdoe-me companheiro, como é que você pode ser meu inimigo? (REMARQUE, 2004, p. 111). 
O texto fala por si. A intensidade que provocou no grupo, que ouviu todo o relato em profundo silêncio e atenção, deu indícios do alcance que teve a narrativa, como elemento de ressignificação dos fenômenos. Trazemos um breve recorte desse rico recurso que utilizamos para concluir a segunda aula e suas possibilidades de sustentar narrativas em torno da franca oposição que, muitas vezes, se estabelece entre as pessoas, entrincheiramentos que separam, afastam, dividem, dicotomizam, que tornam altamente inviável que se possa conceber que ali, do outro lado, habita um semelhante. Banalizam-se as relações, o semelhante, o mal. Os alunos começam a vincular esses elementos aplicados ao trabalho que fazem e ao que terão que enfrentar na posição de gestores de recursos humanos, como pontes entre o patrão e o funcionário. Várias problemáticas foram trazidas ao debate de ideias, refletindo sobre a delicada posição profissional que terão de assumir.

Laplanche (1992) afirma que somos seres autotradutivos e autosimbolizantes. É marca distintiva da natureza humana que uma pessoa produza simbolizações sobre si, sobre o mundo, sobre as coisas que acontecem consigo. Nas palavras de Ernesto Sábato:

O ser humano aprende na medida em que participa na descoberta e na invenção. Deve ter liberdade para opinar, para equivocar-se, para retificar-se, para ensaiar métodos e caminhos, para explorar. De outra maneira, no máximo faremos erudição e, no pior dos casos, ratazanas de biblioteca e papagaios repetidores de livros sagrados. O livro é uma magnífica ajuda, quando não se converte num estorvo. [...] $\mathrm{E}$ isto que digo para os livros, vale também para o professor, que é bom quando não é um obstáculo; o que parece uma piada, mas é uma das calamidades mais frequentes (1997, p. 452, tradução nossa). ${ }^{9}$

Oferecer narrativas é possibilitar a abertura de espaços de produção de novas narrativas, como meio de dar forma, palavra, significado, afeto e sentido aos acontecimentos da vida, o que resulta na possibilidade de pensar a própria realidade. Assim, ao agregar algo próprio, a partir de si mesmo, é possível produzir uma nova possibilidade simbólica singular.

\section{Para finalizar: tempo de elaborar}

Em condições ideais, toda aula deveria ser uma experiência de subjetivação, na qual as pessoas tivessem condições de incorporar algo significativo, pela vivência e pela experiência do encontro, com vistas ao enriquecimento psíquico para a compreensão do fenômeno humano, de si e do outro. Quando Freud ([1937] 1996) incluiu a educação entre os três campos profissionais impossíveis, ao lado da política e da psicanálise, um dos aspectos implícitos em sua afirmação era, justamente, a impossibilidade de, nessas profissões, o ideal ser sempre algo da ordem da ilusão. 
Mesmo que haja um conjunto de boas intenções em nossos atos educativos, segue existindo a impossibilidade de garantir a priori um resultado esperado. E, mesmo quando houver um resultado, não se pode garantir com que qualidade ele se configura, nem qual sua significação. Nessa afirmação, contudo, não há qualquer desprezo de Freud por essas três profissões, nem desprestígio mediante os esforços de cada profissional de conduzir, com todo empenho e dedicação, seu trabalho. Muito pelo contrário, ele reconhece o alto valor social de cada uma delas e a importância da relação de investimento libidinal de cada profissional com seu trabalho e o quanto disso tem potencial para tocar, encantar, seduzir a outra pessoa.

Com base em tais posicionamentos, pensamos ter construído um conhecimento eminentemente humanizado e de potencial humanizante. As aulas subsequentes continuaram a ser desenvolvidas com o mesmo espírito, permitindo, favorecendo e, às vezes, "provocando" que os conteúdos circulassem e fossem sendo, além de inscritos, transcritos e retranscritos, uma vez mais processados e reprocessados.

Fato gratificante foi o relato trazido por uma das alunas no início da última aula, ao contar que, ao final da aula da semana anterior, os colegas foram confraternizar em um bar e lá seguiram as discussões sobre o conceito de banalidade do mal, realizando a união do lúdico com o teórico, talvez com o profundo. Os alunos pareciam querer mostrar que estavam fazendo esforços para estabelecer um vínculo com os temas trabalhados e se apropriar daquilo tudo que lhes foi ofertado como recurso simbólico, de modo a retribuir com aprendizado e com significação. $\mathrm{O}$ sinal de uma marca, de que algo se registrou exatamente onde precisava estar: dentro de cada sujeito, ao seu modo, com suas potencialidades. Um grupo de alunos bem diferente do encontrado no início, agora permeável aos movimentos, inquieto por se deixar tocar pela profundidade dos temas, ávido por poder compreender. Houve o entendimento de que a dimensão da troca humana e dos lugares relativos nessa troca é inalienável da realização da aprendizagem.

Esse é um breve relato de algumas reflexões sobre a docência no ensino superior e seus dilemas. Favorecer o pensamento, utilizando recursos que permitam vincular ao conteúdo que se pretendia socializar dentro da disciplina os elementos que precisam ser construídos internamente, bem como a necessidade de um trabalho elaborativo posterior, favorecido pelo professor, é a nossa expectativa com esta produção, frente aos leitores. 


\section{Notas}

1 Conferência realizada na Faculdade de Psicologia de Rosário (UNR), em 2003.

2 No original: "la producción de subjetividad hace al modo en el cual las sociedades determinan las formas con la cual se constituyen sujetos plausibles de integrarse a sistemas que le otorgan un lugar [...] Van producir un sujeto histórico, potable socialmente".

3 A docência dessa disciplina foi compartilhada entre dois dos autores deste trabalho.

4 As aulas ocorriam quinzenalmente, às sextas-feiras à noite e aos sábados pela manhã.

5 Afirmação apoiada nos escritos de Hannah Arendt, sobre a banalidade do mal, tema que posteriormente foi trabalhado com os alunos e que permitiu a elaboração teórica do que foi experimentado em aula.

6 Ação específica é um conceito freudiano que se refere à "intervenção externa adequada", que presume a posição de "alteridade" do outro, que faz a ação, para a resolução da "tensão de necessidade" (FREUD, [1895] 1996).

7 No original: "quien ha sido socializado y modelado en el contacto con los otros dentro de una cultura dada, adquiere en cierta medida la capacidad de dialogar con una imagen mental del otro al que le supone puntos de vista diferentes a los suyos. Si no ha podido construir esa hipótesis - la de un pensamiento diferente - el intercambio con el otro o con la representación que pueda llegar a tener de esa posibilidad se torna impracticable. Queda en un espacio psíquico en el que la alteridad no resuena porque solo recibe el eco de si mismo".

8 No Dicionário de psicanálise, Roudinesco conceitua significante como "o elemento significativo do discurso (consciente ou inconsciente) que determina os atos, as palavras e o destino do sujeito, à sua revelia e à maneira de uma nomeação simbólica" (ROUDINESCO, 1998, p. 708).

9 No original: "El ser humano aprende en la medida en que participa en el descubrimiento y la invención. Debe tener libertad para opinar, para equivocarse, para rectificarse, para ensayar métodos y caminos, para explorar. De otra manera, a lo más, haremos eruditos y en el peor de los casos ratas de biblioteca y loros repetidores de libros santificados. El libro es una magnífica ayuda, cuando no se convierte en un estorbo. [...] Y esto que digo para los libros también vale para el maestro, que es bueno cuando no es un obstáculo; lo que parece una broma pero es una de las calamidades más frecuentes".

\section{Referências}

ARENDT, Hannah. A crise na educação. [Ensaio] In: Entre o passado e o futuro. 7. ed. São

Paulo: Perspectiva, 2011. p. 21-53.

Eichmann em Jerusalém: um relato sobre a banalidade do mal. São Paulo: Companhia das Letras, 1999.

BLEICHMAR, Silvia. El desmantelamiento de la subjetividad: estallido del Yo. Buenos Aires: Topia Editorial, 2009.

La subjetividad en riesgo. Buenos Aires: Topia Editorial, 2005.

CHARLOT, Bernard. A pesquisa educacional entre conhecimentos, políticas e práticas: especificidades e desafios de uma área do saber. Revista Brasileira de Educação, Rio de Janeiro, v. 11, n. 31, p. 7-18, jan./abr. 2006. Disponível em: <http://www.scielo.br/pdf/rbedu/v11n31/a02v11n31. pdf>. Acesso em: 2 set. 2015.

DEJOURS, Christophe. A banalização da injustiça social. Rio de Janeiro: Fundação Getúlio Vargas, 2000.

FOUCAULT, Michel. A ordem do discurso. 2. ed. São Paulo: Loyola, 1996.

FREUD, Sigmund. Análise terminável e interminável (1937). In: Obras completas. Rio de Janeiro: Imago, 1996. p. 335-443. 
Projeto para uma psicologia científica (1895). In: . Obras completas. Rio de Janeiro: Imago, 1996. p. 225-270.

JANIN, Beatriz. Intervenciones subjetivantes frente al sufrimiento psíquico. In: JANIN, Beatriz, et al. La patologización de la infancia II: problemas e intervenciones en la clínica. Buenos Aires: Noveduc, 2013.

LAPLANCHE, Jean. Novos fundamentos para a psicanálise. São Paulo: Martins Fontes, 1992.

LIBÂNEO, José Carlos. Conteúdos, formação de competências cognitivas e ensino com pesquisaunindo ensino e modos de investigação. In: PIMENTA, S. G.; ALMEIDA, M. I. (Org.). Pedagogia universitária: caminhos para a formação de professores. São Paulo: Cortez, 2011. p. 188-212.

MASETTO, Marcos Tarciso. Competência pedagógica do professor universitário. São Paulo: Sumus, 2003.

PROL, Gerardo; WETTENGEL, Luisa. Clínica psicopedagógica y alteridad: encuentros en el tratamiento de niños e adolescentes. Buenos Aires: Noveduc, 2009.

REMARQUE, Erich Maria. Nada de novo no front. Porto Alegre: L\&PM Pocket, 2004.

ROUDINESCO, Elisabeth. Dicionário de psicanálise. Rio de Janeiro: Zahar, 1998.

SÁBATO, Ernesto. Obras completas: ensaios. Buenos Aires: Seix Barral, 1997. 